\title{
Dijital Oyunlar ve İstihdam: Türkiye İçin Öneriler
}

\begin{tabular}{|c|c|}
\hline 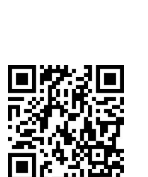 & $\begin{array}{r}\text { Eyüp AKÇETİN } \\
\text { Ufuk ÇELIK } \\
\text { Abdulkadir YALDIR }^{3} \\
\text { Deniz HERAND }^{4}\end{array}$ \\
\hline
\end{tabular}

\section{$\ddot{\mathbf{O z}}$}

Bilgi ve iletişim teknolojilerindeki yeni gelişmeler dijital bir dünyaya adım atmamızı sağlamıştır. Dijital dünya ise dijital bir ekonomiye dönüşmekte ve bu dönüşümden dijital ürünlerin katma değeri doğrudan etkilenmektedir. Hollywood filmlerinin yerine artık dijital oyunlar almıs, dijital oyun sektörü katma değeri ve istihdamı yüksek bir sektör haline gelmiş ve hasılatı ise sinema endüstrisinin iki katını aşmıştır. Dijital oyun endüstrisi kriz dönemlerinde bile etkilenmeden büyüyen sektörlerin başında gelmektedir. Dijital oyun endüstrisi teknolojik olarak en güçlü ülkelerde kendine uygun iklimi bulmuş ve en çok gelir getirici oyunların ve yan ürünlerin tasarlanması ve satışl yine bu ülkelerde yapılmuştır. Dijital oyun endüstrisi istihdam ve sosyal alandaki diğer faaliyetler yanında, sinema gibi birçok sanatsal ögeyi ve sosyal mesaj da barındıran bir alandır. Bu nedenle, Türkiye'nin dünyaya kendini doğru tanitması ve ifade etmesi açısından katma değeri yüksek dijital oyun sektöründe yeterli söz sahibi olması kaçınılmazdır. Bu çalışma kapsamında dijital oyun sektörünün genel olarak ekonomik analizi karşılaş̧ırmalı bir şekilde yapılmaya çalışılmış ve Türkiye'nin bu firsatı en iyi şekilde değerlendirmesine yönelik önerilerde bulunulmuştur.

Anahtar Kelimeler: Istihdam, Dijital Oyunlar, Oyun Endüstrisi ve Türkiye.

Jel Kodlart: E24, E27, C572, D83.

\section{Digital Games and Employment: Recommendations for Turkey}

\begin{abstract}
Recent developments in information and communication technologies have ensured us to take a step into a digital world. The digital world is transforming into a digital economy and this transformation directly affects the added value of digital products. Digital games are now taking the place of Hollywood movies, digital gaming sector has become a sector with high added value and high employment and its revenue has exceeded twice of the film industry. Digital industry is at the forefront of sectors that grow unaffected even in times of crisis. The digital gaming industry has found the appropriate platform in the most technologically strong countries and the design and sale of the most revenue-generating games and by-products were also carried out in these countries. Besides employment and other activities in the social area, digital gaming industry is a field that contains many artistic elements, such as cinema and social message. Therefore, it is inevitable for Turkey to have enough say in the value added digital gaming industry in order to introduce and express itself correctly to the world. In this study, it has been attempted to do economic analysis of the digital gaming industry in general comparatively and proposals have been made for Turkey to evaluate this opportunity in the best possible way.
\end{abstract}

Keywords: Employment, Digital Games, Game Industry and Turkey.

Jel Codes: E24, E27, C572, D83.

\footnotetext{
${ }^{1}$ Yrd. Doç. Dr., Muğla Sitkı Koçman Üniversitesi, Seydikemer Uygulamalı Bilimler Yüksekokulu, e.akcetin@gmail.com ORCID: https://orcid.org/0000-0001-7232-2154

${ }^{2}$ Yrd. Doç. Dr., Bandırma Onyedi Eylül Üniversitesi, Gönen Meslek Yüksekokulu, ucelik001@gmail.com ORCID: https://orcid.org/0000-0003-3063-6272

${ }^{3}$ Yrd. Doç. Dr., Pamukkale Üniversitesi, İ̈BF, Yönetim Bilişim Sistemleri Bölümü, akyaldir@pau.edu.tr ORCID: https://orcid.org/0000-0001-5426-1626

${ }^{4}$ Yrd. Doç. Dr., Marmara Üniversitesi, İşletme Fakültesi, Almanca Enformatiği Bölümü, denizherand@marmara.edu.tr ORCID: https://orcid.org/0000-0001-6813-1427
} 


\section{Giriș}

Onuncu kalkınma planının 2.2. Yenilikçi Üretim, İstikrarlı Yüksek Büyüme ana başlığı altında, 2.2.14. Bilgi ve İletişim Teknolojileri alt başlığının 737. maddesinde; "Sayısal içeriğin gelişmesi ve ticarileşmesi amacıyla, başta oyun olmak üzere mobil uygulama, yazılım ve bilgi teknolojileri hizmetleri desteklenecektir. İnternetteki Türkçe içeriğin nicelik ve nitelik açısından gelişmesi ve erişilebilir olması sağlanacaktır" ifadesi yer almaktadır (Kalkınma Bakanlığı, 2013). Makroekonomik etkilerinin hesaplanması amacı ile Türkiye'nin mevcut durumu, küresel eğilimler ve ülkeye özel durumların ortaya çıkardığı firsatların belirlenmesi ve bunlarla ilgili senaryoların oluşturulması için Makroekonomik Projeksiyonlar ve Fırsatlar Raporu da hazırlanmıştır. Makroekonomik model senaryoları içinde 5. senaryoda savunma, sağlık, mobil uygulama ve dijital oyun gibi stratejik yazılım sektörleri etrafında kümelenme maddesi yer almaktadır. Bilgi ve İletişim Teknolojileri sektöründe 183.000 kişi istihdam edilmektedir. Bu senaryoların uygulanması ile 2013-2023 yılları arasında bu alanda istihdamının \%40 daha büyüyeceği öngörülmektedir. Böylece 50.000 doğrudan, 130.000 dolaylı olarak istihdam oluşturulacağı tahmin edilmektedir (Bilgi Toplumu Dairesi, 2013).

Dijital oyunlar sadece eğlendirmek için yapılmamaktadır. Aynı zamanda propaganda, eğitim ve öğretim faaliyetlerinde de yoğun olarak kullanılmaktadır. Yakın gelecekte dijital çağın dijital üniversitelerinde verilen eğitimlerin tamamı dijital oyunların eğitime entegre edilmesi ile risk almadan deneyimlenerek yapılacaktır. Üniversitelerin hemen hemen tüm bölümlerinde Avatarlar yardımı ile öğrencilerin öğrenme hızına uyum sağlayan yapay zekâ destekli artırılmış gerçeklikle dolu dijital oyunlar çağına girilmiş olacaktır. Klasik eğitim veren üniversiteler hızla dijitalleşmekte ve eğitim içeriklerini oyunlaştırmaktadır. Böylece öğrenme kavramı önem kazanmakta ve öğrenme süreleri kısalmaktadır.

Dijital oyunlar içerikleri bakımından başta sivil toplum kuruluşları olmak üzere çeşitli denetimlerden geçmektedirler. Böylece amaçlarına ve hedef kitlesine verdiği mesajlar bakımından yaş grubuna uygunluk sınıflandırması yapılarak toplumsal bilgilendirme sağlanmaktadır (PEGI, 2003; ESRB, 2017). Kültürel sektör olarak kabul edilen dijital oyun sektörü dijital çağ ile birlikte en gözde sektörlerden biri haline gelmiştir. Dijital oyunların dönüşümü doğrudan teknolojik değişim ve dönüşüme bağlıdır. Oyun sektörü bir anlamada kültürel bir etmen olarak karşımıza çıkmakta, teknolojik dönüşümle değişip gelişerek yumuşak bir güç olarak toplumların kültürünü doğrudan etkilemektedir (European Commission, 2006). Bu nedenle dijital oyun sektörünü sadece eğlendirmek amacı güden bir sektör olarak görmek yanıltıcı olabilir. Çünkü bu sektör ekonomik ve kültürel olarak etki alanı çok yönlü olan bir sektördür. Ekonomik amaçların yanında gizli ve açık kültürel amaçların olduğu bu sektöre küresel güç konumunda olan devletlerin yatırım yapması kesinlikle tesadüf değildir. Fakat bu çalışmada kültürel etmenler ele alınmadan sadece ekonomik temelli bir yaklaşımla dijital oyun sektörü ele alınmıştır.

Dijital oyun sektörü 2016 yılında yaklaşık 100 milyar dolarlık bir pazar haline gelmiştir. 2019 yılına kadar bu sektörün 120 milyar dolarlık bir boyuta ulaşması beklenmektedir (Newzoo, 2016). Gamedevmap sitesine göre dünya genelinde 4445 şirket oyun sektöründe faaliyet göstermektedir. Bu şirketlerin 33'ü Türkiye'de yer almaktadır (Gamedevmap 2.0, 2017).

Dünyada dijital oyun endüstrisi daha çok Amerikan ve Japon şirketlerinin elindedir (Ankara Kalkınma Ajansı, 2016). Amerika kıtasında Hollywood gişe gelirleri 11 milyar dolar iken oyun sektörünün yıllık cirosu 23 milyar dolara ulaşmıştır (Uçkaç ve Tütüncü, 2017). Türkiye'de günde 10 milyon kişiye ulaşabilen oyunlar geliştiren firmalar da mevcuttur. 
Yaklaşık 300 milyon kişinin indirip oynadığı Türk menşeli oyunlar vardır. Türk menşeli oyunlar 150'den fazla ülkede oynanmaktadır (İş Fikirleri ve Girişimcilik Portalı, 2017).

Bu çalışmanın amacı; Türkiye'de son derece dinamik bir gelişme potansiyeline sahip olan dijital oyun sektörünün gelişme potansiyeline dair temel bulguları tespit etmek ve bu sektöre ilişkin gelecek perspektifini ortaya koymaktır. Özellikle kamu politikalarına da belirli alanlarda çeşitli önerilerin yapılması çalışmanın bir diğer amacıdır. Ayrıca dijital oyun sektöründe dünyada söz sahibi olmak için veya dünya genelinde en çok satılan dijital oyunlar geliştirebilmek ve piyasaya sürebilmek için yapılması gereken alt yapı çalışmalarını ortaya koymak ta bu çalışmanın bir başka amacını oluşturmaktadır. Böylece genç ve dinamik bir nüfusa sahip olan Türkiye'nin bilişim alanında yer alan dijital oyun sektörüne istihdam açısından sunduğu firsatlar tespit edilecektir.

\section{Literatür Taraması}

Dünya genelinde 2,2 milyar dijital oyun oynayan kişi mevcuttur. 2017 yılı sonuna kadar oyun piyasasının toplam 108,9 milyar dolara ulaşması beklenmektedir. 2016 yılına göre 2017 yılındaki artışın \%7,8 olacağ tahmin edilmektedir. 2020 yılında ise pazarın 128,5 milyar dolarlık hacme ulaşacağı öngörülmektedir. Bu sektörün en cazip uygulama alanı ise her y1l çarpıcı biçimde büyüyen mobil platformlardır. 46,1 milyar dolarlık bir hacim ile $\% 42$ büyümesi beklenmektedir. 2020 yılına kadar oyun konsolu ile oyun oynama oran $1 \% 30$ civarında kalırken mobil cihazlar ile oyun oynama oranının her geçen gün artarak \%50'lik bir orana ulaşması ve 65 milyar dolarlık bir hacme erişmesi beklenmektedir. Kuzey Amerika'nın küresel oyun pazarından aldığı payın 2017 yılı içinde 27 milyar dolar ile \%25'e ulaşması, Latin Amerika'nın 4,4 milyar dolar ile \%4'e, Avrupa, Afrika ve Ortadoğu'nun 26,2 milyar dolar ile \%24'e, Asya Pasifik hattının 51,2 milyar dolar ile \%47'e ulaşması öngörülmektedir (Newzoo, 2017). Tablo1'de dijital oyun gelirlerinde 2017 y1lı itibariyle ilk 25 ülke verilmiştir.

Tablo 1: 2017 Y1lı İtibariyle Dijital Pazar’1 Büyüklüğüne Göre İlk 25 Ülke Sıralaması (Newzoo, 2017)

\begin{tabular}{|c|l|r|r|r|}
\hline Sira & \multicolumn{1}{|c|}{ Ülke } & \multicolumn{1}{c|}{ Nüfus } & \multicolumn{1}{c|}{ İnternet Nüfusu } & Toplam Gelir (US \$) \\
\hline 1 & Çin & 1.388 .233 .000 & 801.643 .000 & 27.547 .039 .000 \\
\hline 2 & ABD & 326.475 .000 & 261.177 .000 & 25.059 .883 .000 \\
\hline 3 & Japonya & 126.046 .000 & 119.829 .000 & 12.545 .659 .000 \\
\hline 4 & Almanya & 80.637 .000 & 73.098 .000 & 4.378 .066 .000 \\
\hline 5 & İngiltere & 65.512 .000 & 61.620 .000 & 4.217 .715 .000 \\
\hline 6 & Kore Cumhuriyeti & 50.705 .000 & 46.875 .000 & 4.187 .711 .000 \\
\hline 7 & Fransa & 64.939 .000 & 57.381 .000 & 2.967 .052 .000 \\
\hline 8 & Kanada & 36.627 .000 & 33.455 .000 & 1.947 .371 .000 \\
\hline 9 & İspanya & 46.071 .000 & 38.458 .000 & 1.913 .050 .000 \\
\hline 10 & İtalya & 59.798 .000 & 43.141 .000 & 1.874 .608 .000 \\
\hline 11 & Rusya & 143.376 .000 & 113.304 .000 & 1.485 .205 .000 \\
\hline 12 & Meksika & 130.223 .000 & 84.170 .000 & 1.427 .974 .000 \\
\hline 13 & Brezilya & 211.244 .000 & 139.813 .000 & 1.334 .205 .000 \\
\hline 14 & Avustralya & 24.642 .000 & 21.748 .000 & 1.234 .393 .000 \\
\hline 15 & Tayvan & 23.406 .000 & 21.290 .000 & 1.028 .511 .000 \\
\hline 16 & Endonezya & 263.511 .000 & 71.950 .000 & 879.740 .000 \\
\hline 17 & Hindistan & 1.342 .513 .000 & 428.835 .000 & 817.819 .000 \\
\hline
\end{tabular}




\begin{tabular}{|l|l|l|l|r|}
\hline 18 & Türkiye & 80.418 .000 & 49.144 .000 & 773.888 .000 \\
\hline 19 & Suudi Arabistan & 32.743 .000 & 24.799 .000 & 647.424 .000 \\
\hline 20 & Tayland & 68.298 .000 & 31.786 .000 & 597.173 .000 \\
\hline 21 & Malezya & 31.165 .000 & 23.997 .000 & 586.682 .000 \\
\hline 22 & Hollanda & 17.033 .000 & 16.163 .000 & 567.372 .000 \\
\hline 23 & Polonya & 38.564 .000 & 28.657 .000 & 489.208 .000 \\
\hline 24 & İran & 80.946 .000 & 41.682 .000 & 431.917 .000 \\
\hline 25 & Arjantin & 44.273 .000 & 33.447 .000 & 423.405 .000 \\
\hline
\end{tabular}

\section{Yöntem ve Veri}

Çalışma kapsamında küresel dijital oyun sektörü piyasasının mevcut durumu ve geleceğe yönelik tahminler ele alınmıştır. Dijital oyun sektöründe Türkiye ile dünyada ekonomik payları en büyük olan ülkelerin verileri incelenmiştir. Böylece, dijital oyun sektörüne ilişkin bulgular Türkiye ile kıyaslamalı olarak ortaya konulmuştur. Elde edilen veriler ile Türkiye'deki mevcut durum tartışılmıştır. Elde edilen bilgiler 1şığında dijital oyun sektörüne yönelik kamu ve özel sektörde uygulanması gerekli politikalar için çeşitli öneriler sunulmuştur. Ayrıca eldeki bilgiler ile istihdam edilen kişilerin nitel ve nicel özellikleri de ortaya konulmaya çalışılmıştır. Böylece oluşturulacak stratejik hamlelerde en önemli faktör olan insan kaynağının eğitim planlaması için yol haritası ortaya konulmuştur.

$\mathrm{Bu}$ çalışmanın verisini, dijital oyun sektöründe dünyadaki temel eğilimler ile gelişme alanları ve pazar potansiyeli hakkındaki bulgular ve dünya genelinde oyun sektörü için yapılan araştırmalar, raporlar ve bilimsel çalışmalar oluşturmaktadır.

\subsection{Oyun Endüstrisinin Değer Zinciri ve Türkiye}

Dijital Değirmenin kurucusu Ben Sawyer'a göre oyun endüstrisinin altı adet birbiriyle bağlantılı ve farklı değer zinciri katmanı vardır. Bunlar;

$>$ Sermaye ve yayın katmanı: mali olanaklar söz konusudur.

$>$ Ürün ve yetenek katmanı: oyunu ve oyun tasarlayıcılarını kapsamaktadır.

> Üretim ve araçlar katmanı: oyun içeriklerinin üretilmesinde kullanılacak yazılımsal ve donanımsal araçları kapsamaktadır.

> Dağıtım katmanı: oyunların satış, reklam tanıtım, pazarlama ve ürün lojistiğinin yapılmasını kapsamaktadır.

$>$ Donanım katman: oyunun internet alt yapıs1, mobil cihazlar ve konsollar girmektedir.

$>$ Son kullanıcı katmanı: oyunu oynayan oyuncular yer almaktadır (Flew and Humphreys, 2005).

Türkiye' de geliştirilen oyunların hemen hemen tümü yurtdışı piyasalarda pazarlanmaktadır. $\mathrm{Bu}$ sektörde yer almak isteyen yeni bireysel oyun geliştiricileri ve şirketler özelikle sosyal ve mobil oyunlar sayesinde piyasaya çok rahat giriş sağlayabilmektedirler. Lojistik ve dağıtım maliyetlerinin olmaması, yatırımlarda geri dönüş oranlarının çok yüksek olması ve pazarın her geçen gün gelişerek büyümesi gibi nedenlerle dijital oyun sektörüne olan ilgi Türkiye'de her geçen gün artmaktadır (Ankara Kalkınma Ajansı, 2016).

Oyun geliştiricilerinin son 5 yıl içerisinde tüm platformlar için geliştirdikleri oyun sayılarına bakıldığında, \%73 gibi oldukça büyük bir çoğunluğun 5 veya daha az oyun geliştirdiği görülmektedir. Son 5 yılda, yıllık ortalama 6-10 oyun geliştiren geliştiricilerin oranı 
$\% 14$, y1lda ortalama $11-15$ oyun geliştiren geliştiricilerin oran $1 \% 9$ ve yılda ortalama 20 ve üzeri oyun geliştiren geliştiricilerin oranı ise $\% 4$ düzeylerine düşmektedir. Bu da sektörün oyun geliştirme kapasitesinin henüz erken bir aşamada ve düşük düzeyde olduğunu göstermektedir.

Geliștiricilerin \%91,1 gibi çok büyük bir çoğunluğu mobil platformları tercih etmektedir. PC oyunlarında bu oran $\% 64,4$ seviyesinde olup, konsollarda ise $\% 8,9$ seviyesine düşmektedir. Sektörün gelişimi mobil platformların gelişimine paralel olarak sürmektedir. Mobil platformlar çok fazla sermaye gerektirmeyen, geleneksel pazarlama teknik ve yöntemlerine erişim imkânı olmayan geliştiriciler için kısa vadeli ama hızlı gelir elde etme olanağı sunmaktadır. Mobil platformlar özellikle rekabet düzeyi yüksek küresel pazarlara giriş için önemli bir fırsat sunmaktadır. Mobil platformların avantajları yanında, sürdürülebilirliği zor alanlar olması nedeniyle bu platformların çok fazla ön plana çıkmasının sektörün gelişimine orta ve uzun vadede olumsuz etki edebileceği gibi, dezavantajlarının da olduğunu belirtmek gerekir (Ankara Kalkınma Ajansı, 2016).

Oyun geliştiricilerinin genel olarak kullandığı online satış platformları incelendiğinde ise Google Play \%89,6 ve Apple Store ise \% 72,9 ile öne çıkmaktadır. Bu oranları ise Steam \%43,8, Windows Store \%18,8, Amazon App Store \%12,5 ve diğerleri \%12,5 şeklinde takip etmektedir. $\mathrm{Bu}$ istatistiksel bilgiler de sektörde geliştirilen oyunların çok büyük bir çoğunluğunun mobil oyunlar olduğu bilgisini güçlendirmektedir (Ankara Kalkınma Ajans1, 2016).

Oyun geliştiricilerin bilgi kaynağı olarak \%8,9 oranında kamu kurumları, \%22,2 oranında diğer kaynaklar, \%22,2 oranında tedarikçiler, \%26,7 oranında üniversiteler, $\% 28,9$ oranında fuarlar, \%73,3 oranında diğer geliştiriciler ve \%75,6 oranında ise kullanıcılar olduğu görülmektedir (Ankara Kalkınma Ajansı, 2016). Ankara ili baz alındığında üniversiteler oyun geliştirici firmalara fuarlardan bile daha az bilgi kaynağı sunduğu anlaşılmaktadır. Oyun firmaları, özellikle küresel piyasalarda geniş kitlelere oyun satan firmalar, birçok ülkede büyük oranda üniversitelerle iş birliği yaparak çalışmalarını yürütmektedir. Dolayısıyla bu konuda üniversitelerimizin ilgili bölümlerinde gerekli altyapıyı sağlayacak şekilde çalışmalar yapılması kaçınılmazdır.

Oyun geliştiricilerinin teknik kapasiteleri değerlendirildiğinde; geliştiricilerin $\% 65$ 'i teknik kapasitelerinin çok iyi düzeyde, \%30’u iyi düzeyde ve sadece \%6'l1k bir kesim ise kötü düzeyde olarak belirtmişlerdir. Oyun geliştiricilerin büyük bir bölümünün teknik kapasite anlamında yeterli oldukları görülmektedir. Pazarlama olanakları konusunda ise; \%27'lik bir oran iyi ya da çok iyi, \%27'lik bir oran orta ve \%46'llk bir oran ise çok kötü düzeyde olduğu şeklinde değerlendirmektedir. Bu değerlendirmelerden çıkan sonuç ise oyun geliştiricilerin teknik kapasite olarak çok fazla bir sorun yaşamadıkları, fakat ürünlerini pazarlama konusunda çok fazla zorlandıkları ve tanıtım ve reklam konusunda yeterli bilgi birikimine sahip olmadıkları şeklindedir (Ankara Kalkınma Ajansı, 2016).

Devlet desteklerinin oyun sektörünün beklentilerini karşılamaktan çok uzak olduğu görülmektedir. Sektörün zayıf noktası olan reklam ve pazarlamaya yönelik teşviklerin verilmesi ve ayrıca küresel fuarlara akademik ve ticari kurumların katılımlarını artıracak adımların atılması son derce önemlidir. Türkiye'de bu alanda yetişmiş yeterli insan kaynağının olduğunu söylemek de pek mümkün değildir.

Sektörde ihtiyaç duyulan önemli konulardan biri de eğitim desteğidir. Sektörün gelişimi için lisans eğitimi de dahil olmak üzere, işgücü ve personel eğitimi çok önemlidir. Bu kapsamda, eğitim kurumları eğitim altyapılarını güncellemeli ve güçlendirmelidirler. Eğitim ve danışmanlık hizmeti veren kurumların sayısı ve niteliği artırılmalı ve etki alanları genişletilmelidir (Ankara Kalkınma Ajansı, 2016). 


\subsection{Dijital Oyun Sektörü ve Ekonomik Kriz}

Oyun sektörü 100 milyar dolarlık sürekli büyüyen bir sektördür. Krizlerden en az etkilenen ve katma değeri çok yüksek olan bir sektördür.

Dijital oyun sektörünün eko sistemi, yazılımdan donanıma çok büyük etki alanına sahiptir (Ankara Kalkınma Ajansı, 2016). Bu büyük eko sistem içerisinde zayıf halkaya yer yoktur. Bu nedenle kamu ve özel sektör el ele verip ortak projeler geliştirerek bu sektördeki zayıf halkaları güçlendirmelidirler.

Mobil oyun geliştiricilerinin sektördeki ağırlığ 1 bilinmektedir. Dünyada 1 milyar civarında mobil oyun oynayan kişi bulunmaktadır. Fakat, oyun geliştiriciler için rekabetin artmasıyla sektörün cazibesi azalmaktadır. Artan geliştirici ve oyun sayısı rekabetle beraber başarıyı da zorlamaktadır. Örnek olarak; Apple Store'de 400.000'in üzerinde mevcut oyun uygulaması bulunmasına rağmen, günde ortalama 700 yeni oyun daha mağazaya yüklenmektedir. Fakat sektörün gittiği yön nedeniyle PC ve konsollar için geliştirilen oyunlarda bu rakam daha düşüktür. Oyun sektöründe sürdürülebilir bir başarı yakalayabilmek için piyasaya sürülen oyunların gerekli güncellemelerle ve yeni sürümlerle desteklenmesi, veri analizleriyle oyuncu davranışlarının takip edilmesi ve piyasa ve bölgesel koşullara göre ücretlendirme çok önemlidir (Ankara Kalkınma Ajansı, 2016).

Dijital oyun sektörü kriz dönemlerinde diğer sektörlere göre ekonomide can simidi görevi görmektedir. Örneğin Amerika'da bu sektörün büyüme oranı 2005 yılından 2008 yılına kadar \%16,7 iken 2005 yılından 2009 yılına kadar olan dönemde bu oran kriz nedeni ile \%10,6'ya gerilemiştir. Aynı dönemde Amerikan ekonomisinin gerçek büyüme oranları 2005-2008 yılların arasında ortalama \%2,8 iken, 2005-2009 yılları arasında bu oran \%1,4'e gerilemiştir. 2009 yılında bu sektörde görev alan her bir çalışanın yıllık toplam ortalama maaş ve sosyal hak gelirleri 89.781 dolardır (Siwek, 2010). 2012 yılında Amerika'da saniyede 6 adet, yılda 188 milyon adet dijital oyun satışı gerçekleşmiştir (ESA, 2014).

\subsection{Dijital Oyuncular}

Edward Castronova'ya göre (Castronova, 2003) insanlık 1996 yılından bu yana online oyunlara ve sanal dünyaya yapılan büyük bir göçe şahit olmaya başlamıştır. Bu büyük göçün sebebi oyuncuların sanal dünyada gerçek dünyadakinden daha fazla şey başarabiliyor olmasıdır. Oyuncular oyunlarda gerçek hayattakinden daha iyi ve daha fazla geri bildirim alarak daha fazla ödüllendirilmiş hissediyorlar. İnsanlar, gerçek hayatta yapabildiklerinden daha fazla güçlü sosyal ilişkiler kurabiliyorlar. Ayrıca insanların geliri, sanal ekonomide yani dijital oyun sektöründe gerçek dünyadakinden daha fazladır. Yani bu sektör her zaman daha iyi bir yaşam olanağ1 sunmaktadır (Castronova, 2003). Teknolojinin gelişimine doğrudan bağlantılı olan dijital oyun sektöründe yasal alt yapı henüz oluşturulamamıştır. Bu konuda Türkiye'nin de yapması gereken bir dizi faaliyet vardır. Bu nedenle dijital oyun sektörü ele alınırken çok boyutlu ele alınmalı ve hukuki, sosyal ve ekonomik boyutların her biri birbiriyle senkronize olarak düşünülmelidir.

Normal bir oyuncu iki günlük sürede ortalama bir saat oyun oynarken, bu oran Çin'de 6 milyon oyuncuda ortalama haftada 22 saate, yani part-time çalışma süresine yükselebiliyor. İngiltere, Fransa ve Almanya'da 10 milyondan fazla oyuncu haftada ortalama 20 saat zor oyunları oynamaktadırlar. Amerika'da ortalama 13 saat oyun oynanmaktadır. 5 milyondan fazla oyuncu haftalık 45 saat ile full-time 40 saat çalışan bir işçiden daha fazla zaman oyuna 
ayırmaktadır (McGonical, 2011, s. 3-4). Ülkelere göre aktif dijital oyuncu sayıları ve yüzdelik dilimleri Şekil 1'de verilmiştir.

Şekil 1: Dünyada Ülkelere Göre Aktif Dijital Oyuncu Sayısı (Milyon Kişi) ve Yüzdelik Dilimi (McGonical, 2011)

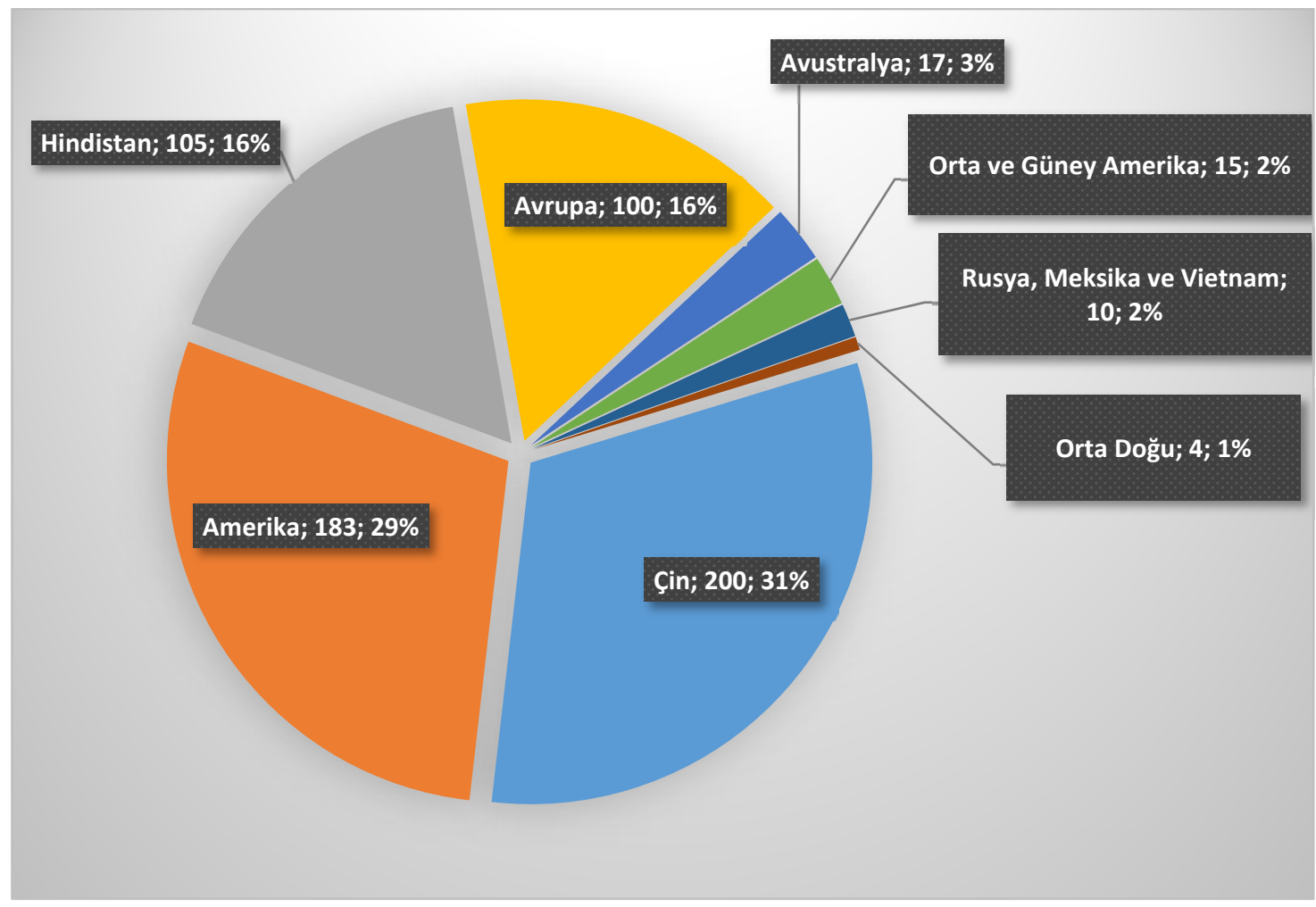

Oyun endüstrisi geniş bant internet yerine kablosuz telefon ağları üzerinden çalışan düşük enerjili konsollar geliştirmektedir. Böylece dünyanın her yerindeki oyuncular, özellikle Hindistan'da, Çin'de, Brezilya'da online olarak oyunlara katılabilecekler. Bu nedenle gelecek on yılda bir milyar daha oyuncunun oyun dünyasına katılması beklenmektedir. Diğer bir deyişle gelecek on y1l içerisinde 1,5 milyar insan, oyun oynayarak oyunda verilen problemleri çözmeye çalışacaktır (McGonical, 2010).

Dijital oyun oynayan oyuncuların büyük çoğunluğunun 16-34 yaş aralığında yer aldığ görülmektedir. 2020 yılı itibariyle en büyük artışın 55 yaş üzeri oyuncularda olacağı öngörülmektedir. Oyuncular daha çok orta gelir grubunda yer alırken en fazla oyun oynayan kesimin ise düşük gelir grubuna sahip kişilerden olduğu görülmüştür (Ankara Kalkınma Ajansı, 2016).

Son 10 y1l içinde Türkiye'de yer alan dijital oyun sektöründe çok ciddi bir hareketlilik gözlenmektedir. Türkiye'de 1 milyona yakın hanede oyun konsolu olduğu tahmin edilmektedir. Avrupa'da oyun sektöründe toplam yıllık gelir, istihdam ve firma Sayısı Türkiye'yi de içerecek şekilde Şekil 2'de verilmiştir. 
Şekil 2: Avrupa'da Oyun Sektöründe Toplam Yıllık Gelir, İstihdam ve Firma Sayısı (EGDF, 2016)

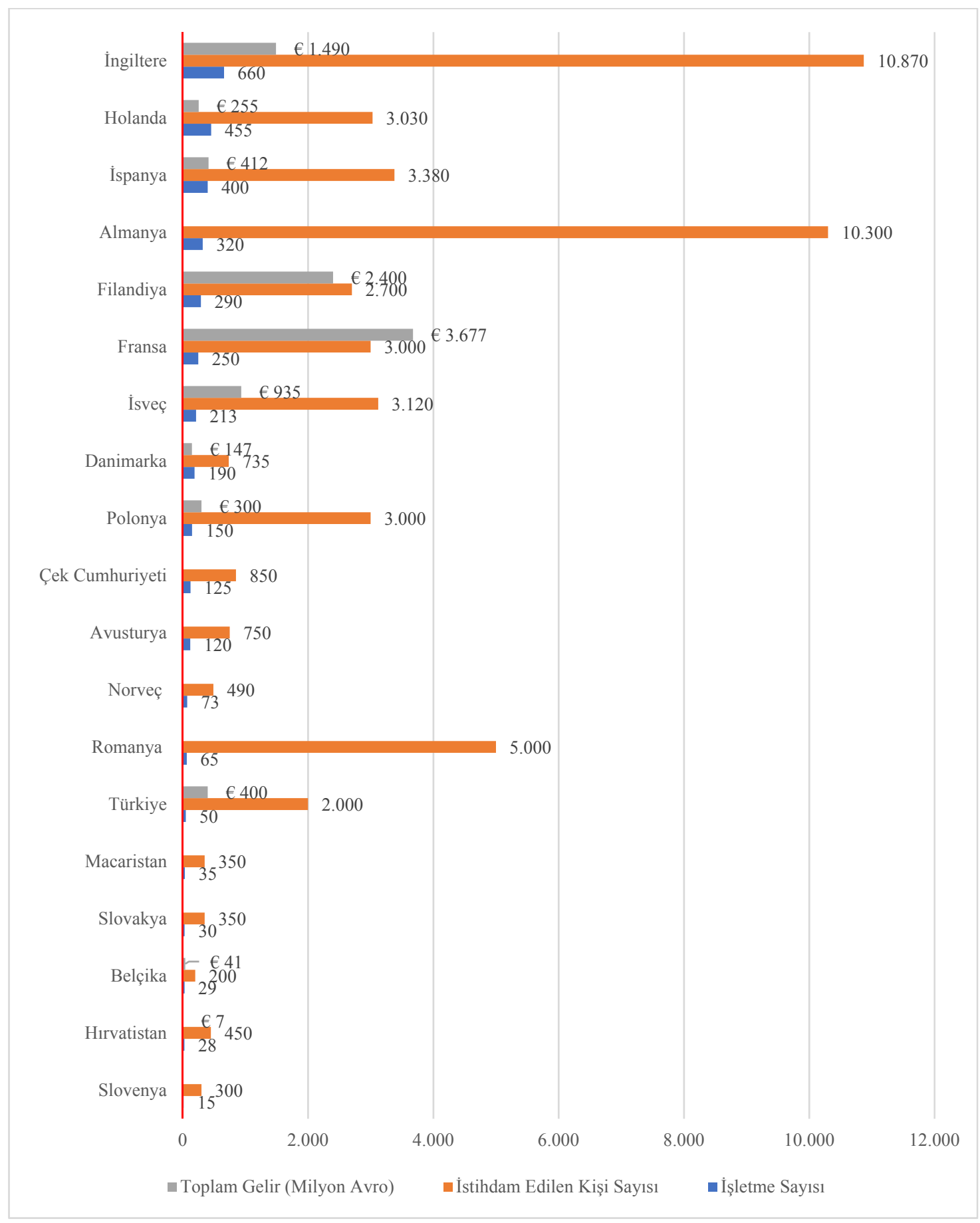

Çalışmanın devamında Türkiye ile beraber Avrupa'nın yanında ABD, Çin ve Japonya gibi dijital oyun sektöründe söz sahibi ülkelere ait veriler de irdelenmiştir.

\subsection{1. $A B D$}

ABD'de dijital oyun sektöründe 1.320 şirket, toplamda ise 1.269 .780 paydaş vardır. 484 üniversitede oyun tasarımına yönelik eğitim bulunmaktadır (ESA, 2017). 2016 yılında ABD'de dijital oyun 
endüstrisi, 2014 yılındakine oranla \%16,5'lik bir artışla 30,4 milyar doları aşan gelir elde etmiştir. Toplam dijital oyun satış1 2016 'da 24,5 milyar doları aşmıştır. 2015 'te, 50 eyaletin tamamında 2.858 bölgede faaliyet gösteren 2.457 video oyun şirketi bulunmaktadır. ABD oyun endüstrisi doğrudan 65.000 'den fazla kişiyi istihdam etmiştir. Bu 65.000 kişinin yaklaşı 28.000 'i büyük oyun yayıncı firmalar tarafından istihdam edilirken, 37.000'i küçük oyun geliştirici firmalar tarafindan istihdam edilmiştir. Oyun sektörü, toplamda 220.000 'den fazla kişiye doğrudan ve dolaylı olarak istihdam sağlamaktadır. 2013-2015 yılları arasında ABD oyun endüstrisindeki doğrudan istihdam, y1llık \%2,9 oranında artmıştır. 2015 yılında maaşlar, işveren emeklilik, sigorta ve devlet sosyal sigortası primleri dahil çalışan başına ortalama yıllık gelir yaklaşık 97.000 dolardır. Bu sektörün ABD GSYİH'ya katkısı 2015 'te 11,7 milyar dolardan fazla olmuştur. Bu katma değer 2013-2015 yılları arasında yıllık \%3,7 oranında büyümüştür (Siwek, 2017).

\subsubsection{Almanya}

Almanya'da oyun pazarı hızlı bir şekilde büyümektedir. Bu nedenle Almanya, Avrupa'nın en büyük ve en cazip oyun piyasasına sahiptir. 26 milyon aktif oyuncuya ev sahipliği yapan Almanya'da, online oyunlara olan talep diğer Avrupa ülkelerinden daha büyük bir hızla artmaktadır. Almanya, Avrupa'da en fazla internet kullanıcısına sahip ülke olduğundan dolayı oyun gibi dijital ekonomi içinde yer alan sektörlere önemli firsatlar sunmaktadır. 2012 yılında Almanya oyun pazarı toplam 1,85 milyar avro ciro elde etmiştir. Özellikle online oyunlar son beş yıl içinde iki basamaklı büyüme hızına ulaşmıştır. 2012 y1lında 2011 'e göre \%80 artarak, oyun oynamak için indirilen uygulama sayısı ise 1,7 milyara ulaşmıştır (GTAI, 2017).

2015 Mart sonu itibarıyla, Almanya'da dijital oyun sektöründe 12,726 kişi, 450 şirkette istihdam edilmiştir. Bu sektörde doğrudan ve dolaylı yoldan oluşturulan istihdam sayısı 30.231'dir. Alman oyun şirketleri, oyunlarını dünya çapında 50'den fazla ülkeye ihraç etmektedirler. Oyun sektöründe en önemli iş alanlarının oyun tasarımı, grafik tasarımı, oyun programcısı ve üreticisinin olduğu görülmektedir. Oyun sektörünün talebi doğrultusunda çok sayıda üniversite oyun alanında lisans ve yüksek lisans eğitimlerine yönelmiştir. Almanya bu alanda küresel pazara mal olan oyunlar geliştirmek istemektedir. $\mathrm{Bu}$ nedenle bu sektöre yönelik mesleki standartlar belirlemekte ve bu alanda verilen eğitimlerin bu standartlara uyumuna yönelik düzenlemeler yapmaktadır (BIU, 2017).

Oyun sektöründe çalışmak için gereken yüksek beceri ve teknik donanım için özel eğitimler gerekmektedir. Bu nedenle Almanya'da bu sektörü desteleyen yaklaşık 40 üniversite ve diğer eğitim kurumu mevcuttur. Bu kurumlar bilgisayar oyunlarının tasarımına yönelik dersler sunmaktadır. Alman oyun endüstrisindeki işgücü maliyetleri ise Alman ekonomisine göre orta düzeydedir. Almanya'da oyun sektörü parasal ve teknik boyutlarda çeşitli teşviklerle devlet tarafindan desteklenmektedir (GTAI, 2017).

\subsubsection{Kanada}

2016 yılında 472 oyun geliştirici firma toplam 20.400 kişiyi doğrudan istihdam etmiştir. Kanada ekonomisine oyun sektörünün katkısı 3 milyar dolardır. Bu sektörde ortalama yıllık toplam maaş 71.300 dolardır. İstihdam edilen kişilerin yaş ortalaması 31 'dir. Bu ortalama, Kanada çalışanlarının yaş ortalamasından 10 yaş daha genç bir ortalamadır. Kanada hükümeti, oyun firmaları ile anlaşarak bu alanda yapılacak eğitime büyük önem vermektedir. Dijital alanda eğitimlerin ilk ve orta öğrenim seviyesine çekilmesi için gerekli çalışmalar başlatılmıştır (ESAC, 2016). 


\subsection{4. İsveç}

2014 yılında İsveç oyun geliştirici firmaların cirosu \%35 artarak 930 milyon avroya ulaşmıştır. Bu sektörde faaliyet gösteren işletmeler son 6 yıldır sürekli kar etmektedirler. Toplam istihdam sayısı her yıl artmaktadır. 2015 yılında bir önceki yıla göre \%23 artarak 583 kişi istihdam edilmiş ve bu sektördeki toplam çalışan sayısı 3.117'ye yükselmiştir. İstihdam da erkeklerin oranı \% 17 artarken, kadınların oranı ise \%39 gibi bir oranda artmıştır. İsveç'in en çok istihdam yapan oyun geliştirici firmaları sırasıyla, DICE 560, King 370, Massive 273, Avalanche 235 ve G5 Entertainment 193 kişiyi istihdam etmektedir. Dünyaca ünlü oyunların grafik motorlarını Dice firması hazırlamaktadır.

2006-2014 yılları arasında bileşik büyüme oranı \%39'dur. Şirket sayında bir yıllık süreçte \%25'lik artış meydana gelmiştir. 213 olan aktif şirket sayısı 266'ya ulaşmıştır. İsveç oyun sektöründe yer alan tüm şirketlerin toplam mali değeri 2,75 milyar avroya ulaşmıştır. İsveç’te yer alan oyun geliştirici firmalar 2010 yılından sonra kurulmuş ve hılı büyüyen işletmelerdendir. Oyunların çoğu uluslararası pazarlarda satışa sunulduğundan bu durum istihdamı da doğrudan etkilemektedir. Özellikle büyük oyun şirketlerinde istihdam edilen kişiler 30'dan fazla farklı ulustandır. Oyun sektörü İsveç'te sürekli gelişmektedir. Bu alanda gelişimin önündeki en büyük engeller; ulusal ve uluslararası kanunlar, düzenlemeler, sermayeye erişim ve küresel oyun piyasasına uygun hareket etmemektir (ASGD, 2015).

\subsubsection{Fransa}

2015 yılında Fransa'da dijital oyunların pazar hacmi 2,87 milyar avroya ulaşmıştır. Bu hacim İngiltere ve Almanya'nın ardından Fransa'yı Avrupa'nın 3. büyük dijital oyun pazarı haline getirmiştir (UKIE, 2017).

\subsubsection{Ingiltere}

Ocak 2017 itibarıyla İngiltere'de 2.088 aktif oyun şirketi bulunmaktadır. İngiltere, Çin, ABD, Japonya, Güney Kore ve Almanya'nın ardından 6. en büyük dijital oyun pazarıdır. İngiltere'de yaklaşık 31,6 milyon kişi oyun oynamaktadır. İngiltere'de dijital oyunlara yapılan harcama tutarı 2015 yılında 4,28 milyar sterlin iken, 2016 yılında bir önceki yıla göre \% 1,2 artarak 4,33 milyar sterline ulaşmıştır. İngiltere oyun şirketlerinin \%68'i 2010'un hemen başında kurulmuştur (UKIE, 2017). İngiltere'de 115 kuruluş, enstitü, üniversite vb. kurum, oyun alanında 315 lisans eğitimi sunmaktadır (Meteos-Garcia, vd., 2014). Bu alanda yetenekli insanlar, Avrupa'dan çıkarak ekonomik olarak imkanların daha iyi olduğu ülkeleri tercih etmektedir. Bu durum Avrupa Birliği tarafindan bir risk unsuru olarak kabul edilmektedir (European Commission, 2006).

2013 yılında İngiltere'de dijital oyun sektöründe 23.900 kişi istihdam edilirken, animasyon film alanında 4.700 kişi istihdam edilmiştir. Dijital oyun firmaları toplamda 1,4 milyar sterlin gayri safi katma değer oluşturmuştur. Devlet hazinesine 429 milyon sterlin katkı sağlamıştır. Animasyon firmaları ise 171 milyon sterlin gayri safi katma değer oluşturmuştur. Devlet hazinesine 52 milyon pound katkı sağlamıştır (Olsberg - SPI and Nordicity, 2015).

\subsection{7. Çin}

Asya pazarında Çin, küresel oyun sektörünün \%25'ini oluşturmaktadır. 2017 y1lında 27,5 milyar dolarlık hacme ulaşması beklenmektedir. Çin'in oyun pazar hacmi 2020 yılında 
\%63'ünü mobil platformlar oluşturacak şekilde yaklaşık olarak 34 milyar dolara ulaşacaktır (Newzoo, 2017).

\subsubsection{Japonya}

PS4 ile oyun konsolları satışında rekor kıran Japonya, 2015 yılında sadece iç piyasada 4 milyon PS4 oyun konsolu satmıştır. Ayrıca Nintendo firmasının oyun pazarında gelecekte tekel olarak kalacağı tahmin edilmektedir. Oyun pazarının büyüklüğ̈̈ 9,6 milyar dolara ulaşmıştır. Her yıl bu sektör \%13'ün üzerinde büyümektedir. Bu sektörün \%60'1 mobil cihazlar üzerinden oynanan oyunlardan oluşmaktadır (UKIE, 2017).

\subsubsection{Avustralya}

2015 yılında Avustralya oyun sektöründen 115 milyon dolar pay almıştır. Bu payın \%81 deniz aşırı ülkelere yapılan satışlardan elde edilmiştir. 2016 ve 2017 yılında oyun geliştirici firmaların \%78'i çalışan ekiplerini güçlendirmeyi ve yeni elemanlar almayi planlamışlardır. 2015-2016 yıllarında 842 yeni eleman işe alınmıştır. Bu elemanların \%33'ü programcı, \%24 grafiker, \%20'si satış-pazarlamadan oluşmaktadır. Oyun sektörü ağırlıklı olarak Melbourne, Birsbane ve Sidney'de yer almaktadır. Oyun şirketlerinin \%24'ü 2012'de sektöre giriş yaparken, \%14'ü 2014 'te ilk kez oyun piyasasında yer almıştır (UKIE, 2017).

\subsubsection{Türkiye}

Avrupa'da 3200'den fazla oyun geliştirme stüdyosu mevcuttur. Bunların sadece 50'si Türkiye'de yer almaktadır. Bu sayı İngiltere'de 660, Hollanda'da 455, İspanya'da 400, Almanya'da 320, Finlandiya'da 290, Fransa'da 250, İsveç'te 213'tür. Toplamda tüm Avrupa'da 45.000 kişi istihdam edilmektedir. En çok istihdam 10.870 ile İngiltere'de iken Almanya 10.300 kişi ile ikinci sırada yer almaktadır. Hollanda, Fransa, İsveç ve Polonya 3.000 civarında istihdam sağlarken, Romanya 5.000 kişi, Türkiye 2.000 kişiye istihdam olanağ sunabilmiştir (EGDF, 2016). Genelde istihdam edilen kişiler diğer sektörlere nazaran daha genç ve dinamik yapıdadırlar. Türkiye gibi genç nüfusa sahip ülkeler için oyun sektörü istihdam açisından bu yönüyle umut vadetmektedir.

Bu sektörde yer alan en büyük 5 ülke toplam oyun gelirlerinin yaklaşık \% 70'ine sahiptir. Türkiye ise 685 milyon dolarlık yıllık gelirle 16. sıradadır (Ankara Kalkınma Ajansı, 2016). Gartner Oyun Sektörü Araştırması Raporuna göre Türkiye'deki oyuncuların 11,4 milyonu dijital oyunlara harcama yapmaktadır. Türkiye'nin genç ve dinamik nüfusunun, günde 39 milyon saat oyun oynandığ tahmin edilmektedir. Diğer taraftan sosyal oyun kategorisinde, Türkiye oyuncu başına 38,4 saat oyun oturumu süresiyle dünya birincisidir (Bilgi Toplumu Dairesi, 2015 s. 89). Newzoo'nun 2012 yılında yaptığı araştırmaya göre Türkiye'de 21.800 .000 kişi oyun oynamaktadır. Bu rakam 2012 yılındaki Türkiye nüfusunun \%52'lik kısmına denk gelmektedir. Türkiye'de oyun için harcanan para 400-500 milyon dolar civarında seyrederken, günlük oyun için harcanan toplam saat 39 milyondur (Newzoo, 2012).

"Oyun geliştiricilerinin son 5 yll içerisinde tüm platformlar için geliştirdikleri oyun sayılarına bakıldığında, oldukça büyük bir çoğunluğun (\%73) 5 veya daha az oyun geliştirdiğ $i$ görülmektedir. Son 5 yılda, yılda ortalama 6-10 oyun geliştiren geliştiricilerin oranı \%14, yılda ortalama 11-15 oyun geliştiren geliştiricilerin oranı \%9 ve yılda ortalama 20 ve üzeri oyun geliştiren geliştiricilerin oranı ise \%4 düzeylerine düşmektedir. Bu da sektörün oyun geliştirme 
kapasitesinin henüz erken bir aşamada ve düşük düzeyde olduğunu göstermektedir. Geliştiricilerin \%91,1'i mobil platformu tercih etmektedir. PC platformda bu oran \%64,4 düzeyinde olup, konsollarda ise \%8,9 düzeyine düşmektedir. Mobil platformların bu kadar yüksek düzeyde tercih edilmeleri ile sektörün gelişim düzeyi hakkında bir ilişki kurulabilir (Ankara Kalkınma Ajans1, 2016)."

Dijital oyunun piyasaya sunulması için programlama, sanat, ses, tasarım, satış, pazarlama, reklam, planlama ve yönetim ekibine ihtiyaç vardır. Ortalama büyüklükte bir stüdyoda yaklaşık 40-50 kişi istihdam edilmektedir. Türkiye'de ise oyun geliştirici ekipler 0-5 kişi arasında oluştuğu gözlenmektedir. Bu şunu göstermektedir; henüz dünya çapında bilinen ve devamı beklenen etkili bir oyun küresel oyun piyasasına arz edilememiştir. Çünkü küresel çapta bir oyun için ekipteki kişi sayısı çok rahat 50-55 kişiye ulaşmaktadır. Türkiye'de oyun geliştirici firmaların ekip sayıları 20'den fazla olan firmaların oranı \%3'tür. (Ankara Kalkınma Ajansı, 2016). Türkiye oyun pazarı büyüklüğü bakımından 755 milyon dolar ile 16. sırada bulunmaktadır. Oyun pazarı içerisinde Türk geliştiricilerinin payının ise yüzde 5 düzeyinde kaldığ1 görülmektedir. Türkiye' de oyun sektöründe 60'a yakın geliştirici şirket bulunmaktadır. Ayrıca henüz şirketleşmemiş olan ekipler de bağımsız olarak oyun geliştirmektedir. Bu şirketlerden önemli bir kısmı Ankara'da bulununken, İstanbul'da genellikle yayıncı, dağıtımcı ve basın-medya alanındaki şirketler bulunmaktadır (Bilgi Toplumu Dairesi 2015 s. 89).

Ankara Kalkınma Ajansının dijital oyun sektörü raporuna göre Ankara' da yer alan oyun tasarımcıların \%2'si kadın, \%98'i erkektir. 2015 yılı verilerine göre dünyadaki bu oranlar ise \%75'i erkek, \%22'si kadın şeklindedir. Oyun tasarımcılarının \%93'ü lisans veya yüksek lisans mezunudur. Buradan hareketle oyun tasarlamak yüksek eğitim ve teknik eğitim gerektirmektedir. Yüksek lisans yapanların \%22'si 25 yaş ve altı, \%32'si 25 yaşından büyüktür. Oyun tasarımcıların çoğu yazılım konusunda eğitim görmüş kesimden oluşmaktadır. Oyun tasarımcıların \%71'i lisans, \%22'si yüksek lisans ve \%7'si daha alt seviyede mezuniyete sahiptir. Doktora yapan oyun tasarımcısı yoktur. Dünyada özellikle ciddi oyun tasarımcıları doktora yapan kişilerden oluşmaktadır. Hatta bir ekipte oyun tasarımcılarının yönetim kadroları, genelde doktoralı bilim insanları tarafından doldurulmaktadır. Oyun tasarımcılarının $\% 44$ 'ü $18-24, \% 37$ 'si $25-34, \% 17$ 'si $35-44$ ve $\% 2$ 'si 45 ve üstü yaş aralığında yer aldığ1 görülmektedir. Yaş ortalamasının yaklaşık 28,11 olduğu tahmin edilmektedir. Bu durum Türkiye gibi genç nüfusa sahip ülkelerde genç istihdamı açısından önem arz etmektedir. Oyun tasarımcılarının \%70'i şirketleşmeyi başarmıştır. Oyun eko-sistemi incelendiğinde şirketleşmemiş bir ekip içinde çalışanlar \%22, şirketleşmiş bir ekip içinde çalışanlar \%13, bireysel geliştiriciler \%48 ve diğer gruplar ise \%17'dir. Dünya genelinde tasarımdan satışpazarlamaya kadar birçok alanda profesyonelleşmiş oyun firmalarına rakip olmak mevcut yapı ile pek mümkün gözükmemektedir. Öte yandan oyun firmalarının \%90’1 5 yıllıktır. Oyun firmalarının \%12'si kalıcı olurken \%88'i yok olup gitmektedir. Oyun firmalarının \%3'ü 20002005, \%9'u 2006-2010 y1lları arasında kurulmuş ve \%88'i ise 2011 y1lı ve sonrasında kurulmuştur. Bu şirketlerin \%3'ünde 20'den fazla kişi, \%8'inde 11-20 kişi, \%18'inde 6-10 kişi $\% 71$ 'inde 1-5 arası kişi istihdam edilmiştir. Bu firmalardan yalnızca \%11'lik bir kesim 10 kişinin üzerinde ekiplerden meydana gelmektedir (Ankara Kalkınma Ajansı, 2016).

Oyun geliştiricilerin gelir kaynakları incelendiğinde; \%57,5 oranında oyun içi reklamlar, $\% 50$ oranında oyun ücretleri ve $\% 42,5$ oranında ise oyun içi satın almalardan oluştuğu görülmüştür. Bu gelirlerin haricinde proje fon gelirleri gibi bireysel destekçilerden gelen diğer gelirler ise kayda değer oranda değildir. Reklam gelirlerinin yüksek oranda olması oyunların daha çok ücretsiz mobil oyunlar olmasından kaynaklanmaktadır. Dolayısıyla oyun geliştiriciler çoğu durumda sadece reklam gelirlerine odaklanarak mobil oyunlara yönelebilmektedirler. 
Ücretli oyunların da sektör için önemli bir gelir kaynağı olduğu görülmektedir. Oyun sektörünün geliştirilmesi, özellikle bireysel yazılım ile mobil uygulamalar ve oyun pazarının desteklenmesi 2015-2018 Türkiye Bilgi Toplumu Stratejisi hedefleri arasındadır (Ankara Kalkınma Ajans1, 2016).

Sektörün gelişmesine katkı sağlayan, özellikle insan kaynaklarının geliştirilmesi için eğitim veren önemli kurumsal yapılar bulunmaktadır. Bu yapılardan biri de Crytek ve Bahçeşehir Üniversitesi iş birliğiyle, Sanal Gerçeklik - Virtual Reality (VR) Teknolojisinin geliştirilmesi amaciyla kurulmuş olan Crytek VR merkezidir. Bu merkezde VR First programı kapsamında Cryengine Academy eğitim programı ile oyun geliştirme alanında dersler verilmektedir. Crytek VR merkezinin ilgili üniversiteler iş birliğinde diğer illerde de kurulması planlanmaktadır (Ankara Kalkınma Ajansı, 2016).

Oyun sektörü ekosisteminin gelişmesi için en önemli kurumlardan biri de Animasyon Teknolojileri ve Oyun Geliştirme Merkezi (ATOM )'dir. ATOM, oyun geliştirme ve animasyon alanında faaliyet gösteren veya ilgisi olan kişilere bir yıl süreyle, eğitim ve danışmanlık desteği yanında, çalışma alanı ve fiziksel-teknik altyapı destekleri de veren ön kuluçka merkezi olarak ODTÜ Teknokent A.Ş. bünyesinde 2008 yilında kurulmuştur. Sektörde yapılan diğer bir etkinlik ise 2014 yılından bu yana değiş̧ik üniversitelerin ev sahipliğinde düzenli olarak yapılan Eurasia Graphics- Uluslararası Bilgisayar Grafiği, Animasyonu ve Oyun Teknolojileri Konferansıdır. Sivil toplum örgütleri olarak ise; Türkiye Oyun Geliştiricileri Derneği (TOGED), Oyun Tasarımcıları, Geliştiricileri, Yapım ve Yayıncıları Derneği (OYUNDER) ve Türkiye Bilişim Derneği (TBD) gibi kuruluşlar bulunmaktadır. TOGED sektördeki paydaşları bir araya getirmek, nitelikli insan gücü yetişmesine katkı sağlamak, kamu bilincini artırmak, uzmanlık alanları oluşturmak ve sektör ile ilgili gerekli standardizasyonu sağlamayı amaçlamaktadır. OYUNDER ise Türkiye'nin oyun endüstrisini temsil eden, üyeleri arasında sektörü temsil eden tüm paydaşların olduğu dernek statüsünde kâr amacı gütmeyen bir kuruluştur. TBD bünyesinde ise bilişim sektörünün geliştirilmesi için Sayısal Oyun Endüstrisi gibi çeşitli uzmanlık grupları kurulmuştur. (Ankara Kalkınma Ajansı, 2016).

Üniversitelerde ise sektörün ihtiyaç duyduğu insan kaynaklarına yüksek lisans programları ile destek verilmektedir. Hacettepe Üniversitesi- Bilişim Enstitüsü'nde Bilgisayar Animasyonu ve Oyun Teknolojileri alanında Tezli ve Tezsiz Yüksek Lisans Programları bulunmaktadır. Bilgi Üniversitesi- Uygulamalı Bilimler Yüksek Okulu'nda Dijital Oyun Tasarımı Bölümü bulunmaktadır. ODTÜ'de Oyun Teknolojileri Yüksek Lisans Programı, İzmir Ekonomi Üniversitesi'nde ise Bilgisayar Oyunları ve Teknolojisi Yüksek Lisans Programı bulunmaktadır. İletişim fakülteleri bünyesinde oyun sektörünü destekleyici birçok program bulunmaktadır. Bunların yanında, TOGED, ODTÜ, TED ve İSSKUR gibi kurumlar oyun sektöründe ihtiyaç duyulan insan kaynakları için kısa süreli fakat yoğun yeni bir programlar üzerinde çalışmaktadır. (Ankara Kalkınma Ajansı, 2016).

1999 yılında Almanya'da 3 Türk kardeş tarafından kurulan ve birçok ödül kazanan oyunlar geliştiren Crytek firmasının Kiev, Budapeşte, Sofya, Seul, Şangay ve İstanbul gibi şehirlerde de ofisleri bulunmaktadır. Geliştirdiği oyunlarda Cryengine 3 boyutlu oyun teknolojisini kullanan firma, kendilerine has iş modeli ile geliştiricilere oyunlarını kodlar kullanarak geliştirme firsatı da sunmaktadır (Ankara Kalkınma Ajansı, 2016). 


\section{SONUÇ}

Türkiye'de dijital oyun sektörü henüz tam olarak bilinen bir sektör haline gelememiştir. Çünkü Türkiye'de küresel piyasalarda milyonlarca kişiye satılan ve devamı beklenen bir oyun henüz ortaya çıkarılamamıştır. Bu nedenle küresel rekabette henüz yer edinebilmiş değildir. Türkiye'nin dijital oyun sektöründeki hak ettiği yeri alabilmesi için bu sektörün yapısı ve ihtiyaçlarına yönelik yeni destek programlarının bir an önce oluşturulması gerekmektedir. Üniversitelerdeki ilgili eğitim programlarının oyun sektörünün ihtiyaçlarını karşılayacak şekilde güncellenmesi önemlidir. Örgün eğitim dışında da dijital köyler kurularak bilgi teknolojilerinde kümelenmeli ve birçok firma ortak ar-ge ve eğitim çalışması yürütmelidir. Sürdürülebilir ve uzmanlaşmış iş ve kuluçka modellerinin geliştirilmesi ve oyun sektöründeki yenilikçi eğilimleri takip etmek ve pazarlama, muhasebe ve reklam gibi alanlarda ortak hizmet üretmek üzere merkezlerinin kurulması kaçınılmazdır.

Oyun firmaları için serbest geliştirme bölgeleri tasarlanmalı, kurulmalı ve bu sektöre yönelik kümeleme uygulamaları devreye sokulmalıdır. Oyun alanında eğitim programlarının yaygınlaştırılması, özellikle orta öğrenimde sektöre uygun proje okullarının kurulması, üniversitelerde oyun tasarım bölümlerinin yaygınlaştırılması gereklidir. Özellikle ciddi oyun yapımının özendirilmesi Türkiye gibi genç işsizlerin bulunduğu ve kronik işsizlik problemi olan ülkelerde önem arz etmektedir.

Dijital oyunların kullanımı mobil cihazlara doğru kaymaktadır. Ayrıca dijital oyunlar fiziki kopya yerine indirilebilir dijital kopya halinde tercih edilir hale gelmiştir. Bu nedenle mobil cihazlarda oynanabilen büyük veri kapasiteli oyunların tasarımına odaklanmak gerekmektedir. Dijital oyunların ürün yaşam eğrisi kısadır. Bu nedenle tasarlanan oyunların tanıtımı, satışı ve pazarlaması için oyuna uygun stratejilerin geliştirilmesi gereklidir. Dinamik ve teknolojik yeniliklerle birlikte sürekli dönüşen bir sektör olan dijital oyun sektöründe iş modelleri ve pazarlama olanakları olarak da sürekli yeni alternatifler ve firsatlar ortaya çıkmaktadır.

Bu bağlamda Türkiye açısından dijital oyun sektörüne yönelik önemli bulduğumuz öneriler aşağıda sıralanmıştır;

$>$ Yaratıcı endüstriler ve oyun özelinde ihracat grubunun oluşturulması.

$>$ Mesleki Eğitim ve Öğretim Sistemini Güçlendirme Projesi (MEGEP) gibi mesleki standartlarının ortaya konması.

$>$ Mesleki Yeterlilik Kurumu (MYK) ve Türkiye İş Kurumu (İŞKUR) gibi kurumların etkinliğinin artırılması ile nitelikli insan kaynağına yönelik çalışmaların güçlendirilmesi.

$>$ Eğitim faaliyetlerinin artırılması ve desteklenmesi.

$>$ Dijital oyun sektörüne yönelik devlet destek ve teşviklerin yapılandırılması.

$>$ Oyun geliştiriciliğinin özendirilmesi ve anlatılması.

$>$ Oyun konusunda toplumun algı ve okuryazarlık seviyesinin güçlendirilmesi.

$>$ Finansman erişimini teşvik edecek düzenlemelerin yapılması.

$>$ Akademi ve sektör işbirliğinin teşvik edilmesi.

$>$ Yaratıcı endüstriler arası işbirliğinin artırılmasının teşvik edilmesi.

$>$ Oyun yapımcılığı ve yayıncılığı alanlarında tecrübenin yükseltilmesi.

$>$ Hukuki, mali ve idari alanlarda gerekli düzenlemelerin yapılması.

$>$ Türkiye ve dünyada ulusal ve uluslararası etkinliklere katılımın özendirilmesi gereklidir. 
Türkiye 2023 hedeflerini tutturmada bu öneriler doğrultusunda hareket ederse dijital oyun sektörünün katkısını fazlasıyla görecektir. OYUNDER'e göre, sektörün gelişimi için gereken alt yapının hazırlanması ile 2023 yılında bu sektörün oluşturacağı katma değerin çok fazla olacağı beklenmektedir. Böylece oyun endüstrisinde 10 milyar dolarlık bir ekonomik büyüklük oluşarak doğrundan ve dolaylı olarak 500 bin kişinin istihdam edileceği tahmin edilmektedir. Türkiye oyun sektörünün dünya üzerinde bir marka haline gelmesi durumunda, oyunlar üzerinden Türkiye'nin tanıtımı ile 20-25 milyar dolarlık katma değer artışı da gerçekleşebilecektir.

Küresel oyun sektörü dünyada yeni bir medyatik güç haline de gelmiştir. Bu nedenle Türkiye TRT İngilizce ve Arapça kanalları ile amaçlamış olduğu tüm hedefleri dijital oyunlar ile rahatlıkla yapabilir. Batı uygarlığı sanatsal tasarımlarla yumuşak bir güç olarak dijital oyunlar vasitasıyla propaganda yapmaktadır. Türkiye'nin bu alanda ivedilikle önlem alması, önce kendi gençliğinin değerler eğitimi için oyunlar tasarlaması, sonrasında yapılan olumsuz propagandalara karşı yumuşak güçle mücadele alanları oluşturması gereklidir. Çünkü birçok oyunda milli ve manevi değerlerimiz ile uyuşmayan içerikler gençlerimize sunulurken bazı oyunlarda Müslümanlar terörist gibi gösterilmektedir. Bu nedenle aynı biçimde yanıt vermek, küresel çapta aynı biçimde en azından eş bir ürün ortaya koyarak mümkün olacaktır.

\section{Kaynaklar}

Ankara Kalkınma Ajansı (2016), “Dijital Oyun Sektörü Raporu”, Ankara Kalkınma Ajansı, Ankara.

ASGD (2015), “Game Developer Index 2015”, Association of Swedish Game Developers, Stockholm.

BIU (2017), "Labour Market", Bundesverband Interaktive Unterhaltungssoftware e.V., https://www.biu-online.de/en/labour-market/ (Erişim Tarihi: 12.06.2017).

Bilgi Toplumu Dairesi (2013), "Bilgi Toplumu Stratejisinin Yenilenmesi Projesi Makroekonomik Projeksiyonlar ve Firsatlar Raporu", T. C. Kalkınma Bakanlığı, Ankara.

Bilgi Toplumu Dairesi (2015), “2015-2018 Bilgi Toplumu Stratejisi ve Eylem Planı”, T. C. Kalkınma Bakanlığı, Ankara.

Castronova, E. (2003), “On Virtual Economies”, The International Journal of Computer Game Research, 3(2).

EGDF (2016), "How to Enable Digital Growth in Europe?", European Games Developer Federation, Helsinki.

ESA (2014), "Games: Improving the Economy", Entertainment Software Association, http://www.theesa.com/wp-content/uploads/2014/11/Games_Economy-11-4-14.pdf (Erişim Tarihi: 12.06.2017)

ESA (2017), "Impact of the Video Game Industry: State by State", https://www.areweinyourstate.org/ (Erişim tarihi: 12.06.2017)

ESAC (2016), "Essential Facts", Entertainment Software Association of Canada, Toronto.

ESRB (2017), "ESRB Ratings 2016", The Entertainment Software Rating Board, http://theesa.ca/wp-content/uploads/2016/11/2016_booklet_Web.compressed2.pdf Erişim Tarihi: 12.06.2017). 
European Commission (2006), "The Economy of Culture in Europe", European Commission, Brussels.

Flew, T. and Humphreys, S. (2005), "Games: Technology, Industry, Culture”, New Media: An Introduction (Second Edition), Oxford University Press.

Gamedevmap 2.0 (2017), "Living Map and Catalog of Game Development Organizations", https://www.gamedevmap.com/index.php? country $=\&$ state $=\&$ city $=\&$ query $=\&$ type $=$ Seri ous\%20Games (Erişim Tarihi: 12.06.2017)

GTAI (2017), “Gaming Industry: Germany Conquers European Gaming Market”, http://www.gtai.de/GTAI/Navigation/EN/Invest/Industries/Digitaleconomy/gaming.html\#620052 (Erişim Tarihi: 12.06.2017).

İş Fikirleri ve Girişimcilik Portalı (2017), "Dijital Oyun Sektörüne Yatırım Yapın”, http://www.isfikirleri-girisimcilik.com/dijital-oyun-sektorune-yatirim-yapin/3 (Erişim Tarihi: 12.06.2017).

Kalkınma Bakanlığı (2013), “Onuncu Kalkınma Planı 2014-2018”, T. C. Kalkınma Bakanlığg, Ankara.

McGonical, J. (2010), "Gaming Can Make a Better World", TED - Ideas Worth Spreading, https://www.ted.com/talks/jane_mcgonigal_gaming_can_make_a_better_world (Erişim Tarihi: 12.06.2017).

McGonical, J. (2011), "Reality is Broken: Why Games Make Us Better and How They Can Change the World", Penguin, New York.

Meteos-Garcia, Juan., Bakhshi, H., and Lenel, M. (2014), “A Map of the UK Games Industry”, Nesta, London.

Newzoo (2012), “Türkiye Dijital Oyun Pazarı 2012'de 450 Milyon Dolara Ulaşacak”, Newzoo: Insights Solutions, https://newzoo.com/about/press/press-releases/turkiye-dijital-oyunpazar-2012-de-450-milyon-dolara-ula-acak/ (Erişim Tarihi: 12.06.2017).

Newzoo (2016), “Global Games Market Report: An Overview of Trends \& Insights”, Newzoo: Insights Solutions, http://resources.newzoo.com/global-games-market-report (Erişim Tarihi: 12.06.2017).

Newzoo (2017), “The Global Games Market will Reach \$108.9 Billion in 2017 with Mobile Taking 42\%", Newzoo: Insights Solutions, https:/newzoo.com/insights/articles/theglobal-games-market-will-reach-108-9-billion-in-2017-with-mobile-taking-42/ (Erişim Tarihi: 12.06.2017).

Newzoo (2017), “Top 100 Countries by Game Revenues", Newzoo: Insights Solutions, https://newzoo.com/insights/rankings/top-100-countries-by-game-revenues/ (Erişim Tarihi: 12.06.2017).

Olsberg - SPI and Nordicity (2015), "Economic Contribution of the UK's Film, High-End TV, Video Game, and Animation Programming Sectors", http://www.o-spi.co.uk/wpcontent/uploads/2015/02/SPI-Economic-Contribution-Study-2015-02-24.pdf (Erişim Tarihi: 12.06.2017).

PEGI (2003), “About PEGI: What are ratings?”, The Pan-European Game Information, http://www.pegi.info/en/index/id/23 (Erişim Tarihi: 12.06.2016). 
Siwek, S.E. (2010), “The Video Games in the 21st Century: the 2010 Report”, Entartainment Software Association, Washington.

Siwek, S.E. (2017), "Video Games in the 21st Century: the 2017 Report", Entartainment Software Association, Washington.

Uçkaç, F. ve Tütüncü, E. (2017), "111 Milyar Dolarlık Oyun”, The Brand Age, http://thebrandage.com/111-milyar-dolarlik-oyun/ (Erişim Tarihi: 12.06.2017).

UKIE (2017), "UK Video Games Fact Sheet", The Association for UK Interactive Entertainment, https://ukie.org.uk/sites/default/files/UK\%20Games\%20Industry\%20Fact\%20Sheet $\% 20$ 20\%20March\%202017.pdf (Erişim Tarihi: 12.06.2017). 


\section{EXTENDED ABSTRACT}

\section{DIGITAL GAMES AND EMPLOYMENT: RECOMMENDATIONS FOR TURKEY}

The digital gaming industry has found its own climate in the technologically strongest countries and the design and sale of games and by-products that generates the most revenue are also being done in these countries. The digital gaming industry, besides employment and other activities in the social field, also contains many artistic elements and social messages. We have been through those times that movies are the subject of games, now we are experiencing a new era where games are being transformed into films. Thus, digital games have become a new media power, a propaganda tool, and a soft power that provides the ideational transformation to convince the masses. Therefore, Turkey can also support all of her goals that was aimed when the TRT World and TRT Arabic had established, via digital games. It is inevitable for Turkey to have a word in the digital game sector with high added value, in order to present and express herself in an appropriate way to the world. In this study, making an overall economic analysis of digital games industry have been attempted in a comparative manner and suggestions for Turkey in order to evaluate this opportunity well were made. Identifying the key findings regarding the growth potential of the digital gaming industry and revealing the future perspective of this sector for Turkey constitutes the main objectives of this study. Making varying suggestions in certain fields regarding the public policies is another purpose of this study. In addition, it was discussed in the scope of this study to reveal what infrastructure works needed to be done in the digital game sector in order to be able to develop and sell the most sold digital games worldwide and to have a say in the world. Unfortunately, digital game sector has not become a well-known sector in Turkey, yet. Because a game, that is sold in the global markets to millions of people, and whose sequels are waited has not been conceived and made its way in the global competition yet. To enable Turkey to take its deserved place in the digital games industry, new support programs tailored to the needs and the structure of this sector must be established as soon as possible. It is important that the relevant education programs in universities to be updated to meet the needs of the gaming industry. Apart from the formal training, digital villages should be established and clustered in information technologies and many companies should carry out joint research and education. It is inevitable to develop sustainable and specialized business and incubator models and to follow innovative trends in the gaming industry and establish centres to produce common services in areas such as marketing, accounting and advertising. Thus, having a young and dynamic population, it is inevitable for Turkey to look at the digital games industry within the IT field, for employment and to benefit from the opportunities it offers. If Turkey will move with the suggestions presented within the scope of this study, the contribution of the digital games sector regarding the fulfilment of the 2023 goals will be highly appreciated. 